\title{
Perceived stress of Jordanian parents: A comparative study between mothers and fathers
}

\author{
Rami Masa'Deh *1, Hala Bawadi ${ }^{2}$, Ahmad Saifan ${ }^{1}$, Mohannad AbuRuz ${ }^{1}$ \\ ${ }^{1}$ School of Nursing, Applied Science Private University, Amman, Jordan \\ ${ }^{2}$ School of Nursing, The University of Jordan, Amman, Jordan
}

Received: June 24, 2015

Accepted: August 6, 2015

Online Published: August 21, 2015

DOI: $10.5430 /$ jnep.v5n11p89

URL: http://dx.doi.org/10.5430/jnep.v5n11p89

\begin{abstract}
Objective: To investigate perceived stress levels of Jordanian parents and compare their levels of stress in form of couples. Background: Being a parent is a stressful experience for both parents. Gender and cultural background of the parent has an effect on stress perception. However, there is limited research in the Arabic countries on the differences between parents in their stress level from the cultural perspective.

Methods: The study is based on a sample of 528 couples that have healthy children in Jordan. Parents completed a demographic checklist and a perceived stress scale.

Results: There was a significant difference in stress levels between mothers and fathers, with mothers having significantly higher stress scores. The mean stress score for mothers was $17.94(\mathrm{SD}=6.41)$ compared with $15.13(\mathrm{SD}=7.12)$ for fathers, $p<.001$. The eta squared statistic $=0.16$ indicated a large effect size. A Pearson product-moment correlation coefficient showed that there was a positive correlation between maternal and paternal stress levels $(r=0.574, \mathrm{n}=528, p<.001)$.

Conclusions: The study concluded that parenting children is stressful for both parents; and that in couples parental stress levels correlated with each other. Implications for nursing: Investigating differences in stress between mothers and fathers in Jordan may be helpful when designing interventions to reduce stress and an individual parental support programme may be needed to buffer their stress.
\end{abstract}

Key Words: Gender, Jordan, Parent, Stress

\section{INTRODUCTION}

Many authors believe that the demands associated with caring for children are stressful for both parents. ${ }^{[1]}$ Mothers and fathers reported and perceived stress differently. ${ }^{[2-4]}$ Lazarus has defined stress as a mismatch between perceptions of environmental demands and personal resources. ${ }^{[4]}$ Signs of stress can be cognitive, physical, emotional, and behavioural. ${ }^{[6,7]}$ It is well acknowledged that stressful events may increase the risk of disease/disorder when the available resources are insufficient to balance the demands. ${ }^{[1]}$ Two internal processes are thought to play critical roles as mediators of the relationship between exposure to potential stressors and health-related outcomes. ${ }^{[8]}$ First of all, personal appraisal process mediates the relationship between potential and actual stressors. Secondly, personal coping process mediates the association between actual stressors and strain. ${ }^{[8]}$ All these processes should be considered when discussing stress levels differences between people. ${ }^{[9]}$

Coping and social support could help people to face the stress. However, gender was found to have an effect on how Jordan.

*Correspondence: Rami Masa’Deh; Email: r_masadeh@asu.edu.jo; Address: School of Nursing, Applied Science Private University, Amman, 
people evaluate, perceive and respond to stressors. ${ }^{[5,10]} \mathrm{A}$ meta-analysis of 26 studies investigating sex differences in coping showed that women most often favour the use of emotion-focused coping and recruit social support from the people surrounding them. In contrast, men are more likely to face stressful situations in a direct way, as they use problemfocused coping styles. Moreover, the meta-analysis found that in approximately $70 \%$ of the reviewed studies women appraised stressors as more stressful than men whereas no gender differences have been highlighted in the remaining $30 \%$ of the studies which have been investigated. ${ }^{[11]}$

In terms of social support, it has been found that when women and men struggle with the same stressful event they have differences in the source of social support and the way of accessing it. ${ }^{[12]}$ A study of 279 participants of both gender employees in similar professions were taken from the Swedish population. Social support among both genders was investigated and found that men in general, access and use social support less often and to a lesser extent than women. Men are also less influenced by social activity, and therefore, their coping usually does not involve as many interpersonal relationships as for women. ${ }^{[13]}$ However, this study represented the Swedish population and particularly those in a working environment. These findings are consistent with another study which found that females used greater emotional-expressive coping than males. ${ }^{[14]}$

Most reviewed research articles that examined parental stress focused on parental stress when having children with disorders such as epilepsy, cerebral palsy, cancer, diabetic, genetic disorders and autism. ${ }^{[15-19]}$ For example, Masa'Deh et al. conducted a study of parents having children with cancer; this study found that mothers reported higher stress levels than fathers. ${ }^{[3]}$ However, very few studies have examined the stress levels in parents with healthy children.

The reviewed literature showed that being a parent is a stressful experience. To our knowledge, so far, in Jordan, no study has examined parental stress levels and there are no active parental support programmes. Also, it was clear from the literature that gender may affect perceived stress levels. Therefore, it was crucial to compare the stress levels between mothers and fathers by using a large representative sample to identify the difference in stress level between genders. The purposes of the study were to assess parental perceived stress levels and make comparisons between both parents. In this study, therefore, stress levels for mothers and fathers parenting children in school-based population in Jordan were assessed. The resulting could help in understanding the parental gender effect in perceived stress in parents in Jordanian context.
Research questions: (a) do parents differ in their perceived stress levels; and (b) is there a relationship between mothers' levels of stress and fathers' levels of stress within a family?

\section{Methods}

\subsection{Design}

Due to the fact that the aim of this study is to measure and compare stress levels of mothers and fathers parenting healthy children in Jordan, a descriptive comparative study design was used and found to attain the aim of the study.

\subsection{Ethical considerations}

Approval was obtained from the Jordanian Ministry of Health $(\mathrm{MoH})$ and all schools where the study has been conducted and permission to proceed with the study was secured. The researcher had an access to various primary schools in Jordan; the participants were recruited through visiting different primary schools in the largest cities in Jordan (i.e., Amman, Irbid and Zarqa). Two teachers were appointed by each school and were licensed as a research assistant, distributed the information sheets, the consent form and the questionnaires to the students to give them to their parents. Those who were interested have filled the papers and returned them back to the school. The researcher then collected the papers from the schools. Moreover, participant informed consent, voluntary participation and confidentiality were guaranteed.

\subsection{Participants and settings}

Sample size was calculated; to reach a statistically significant results using a power of 0.8 and an $\alpha$ of 0.05 , a sample size of 500 for the each group (i.e., mothers and fathers) was necessary. A convenience sample of parents of school-based children from nine primary schools (private and governmental) located in three major cities in Jordan (i.e., Amman, Irbid and Zarqa) was invited to participate. More than three quarters of the Jordanian population live in the above cities. ${ }^{[20]}$

\section{Inclusion criteria:}

(1) Jordanian nationality;

(2) Parenting at least one child who is older than 6 years old and younger than 13 years;

(3) Reads and writes the formal language in Jordan (i.e., Arabic);

(4) Forming a couple (mother and father).

Due to the fact that the main aim of the current research study is to assess parental stress in normal life situation, parents were excluded if they have any seriously ill child (as defined by the parents) and/or did not form a couple.

In this study, 685 couples parenting school children were invited to participate, 605 consented to participate, and 560 
couples have fully completed and returned the questionnaires. Of those, 32 couples were excluded (i.e., 10 participants did not form a couple and 22 families were parenting ill children). At the end, 528 couples were included in this study.

\subsection{Measures}

\subsubsection{Demographic data and characteristics check list}

Demographic characteristics were collected through a developed Arabic checklist. The checklist includes some information about parent's age, financial and work status, number of the children in the family, level of education and health status of their children.

\subsubsection{The Arabic version of perceived stress scale 10-items questionnaire (PSS10)}

The Perceived Stress Scale (PSS10) has been used to assess perceived stress levels in a normal population of males and females 18 years of age and older who were residents in the United States of America. ${ }^{[21]}$ It has also been used to measure perceived stress in university students in Jordan. ${ }^{[22]}$ The previous studies collected data from various age groups of people and from differing life situations and cultures. For example, approximately $75 \%$ of the total US sample (i.e. 2,387,960 males and 1,427 females) was between 18 and 54 years old and approximately $87 \%$ of the Jordanian students (i.e., 24,179 males and 162 females) were between 17 and 22 years old. The differences of age groups, life situations and/or cultures may lead to different PSS10 findings. ${ }^{\left[{ }^{2]} \text { More- }\right.}$ over, the US results suggested that PSS10 results may differ across different races. ${ }^{[1,21]}$ However, the authors recommended further testing of the PSS10 to establish its construct validity and ensure that the scale is culturally sensitive. They also highlighted the need of having a more divers sample includes both genders.

The PSS10 has been translated to different languages including Arabic, Spanish, Turkish, Mexican, Swedish, Italian, Greek, Bulgarian, Chinese, Thai, Japanese, Persian, and Hungarian. ${ }^{[23]}$ Hamdan-Mansour and Dawani used an Arabic version of PSS10 to study stress among university students in Jordan. ${ }^{[22]}$ They reported an internal consistency of 0.68 . Using the pilot data of a study investigating stress and health among working Jordanian women, Hattar-Pollara and Dawani reported a Cronbach alpha of the Arabic translated version of 0.86. ${ }^{[24]}$ Moreover, the Arabic version has been used in Lebanon to measure stress in pregnant and post partum women. ${ }^{[25]}$ All of these supported the validity of PSS10 to be used in among Middle East culture. In this study, Perceived Stress Scale 10 (PSS10) was used to measure the participants stress level.

Due to the simplistic nature of this questionnaire, the parPublished by Sciedu Press ents should have no difficulties or burden in participation. ${ }^{[26]}$ Moreover, the Arabic version of PSS10 has a good reliability and has been previously used in Jordan. ${ }^{[22,27]}$ This held relevance to this investigation with its focus on individual perceived stress of those parenting children in Jordan.

The PSS10 is a rating scale. ${ }^{[28]}$ Item responses range from never (0) to very often (4). Scores can range from 0 to 40 , with higher scores indicating greater stress. The total score is calculated by adding the scores of each question, after reversing the negative questions. The PSS10 is not a diagnostic instrument, so there are no cut-offs. There are only comparisons between people in a given sample.

Before starting the study, the research process was checked by distributing all papers to the participants. The first twenty participants were considered as a pilot to assess feasibility; because there were no amendments in the process, the data collected from those participants was considered in the research analysis.

\subsection{Data analysis}

The Statistical Package for the Social Sciences (SPSS21) was used to analyse the data. ${ }^{[29]}$ Descriptive statistics were illustrated to describe the characteristics of study sample. Paired $\mathrm{t}$-test was used to examine the differences between maternal and paternal perceived stress levels, in couple settings. According to Pallant, an effect size of 0.01 is considered small, 0.06 moderate, and 0.14 is considered a large effect size. ${ }^{[30]}$

\section{RESUlts}

\subsection{Demographical characteristics}

Tables 1 and 2 Illustrates that the respondents $(n=528)$ were couples parenting children within the general school population in Jordan (i.e., 528 mothers and 528 fathers), with respondent rate of with $87.3 \%$. Mothers were younger than the fathers in $94.5 \%$ of the respondents. The age of the father ranged from 27 to 74 years while it ranged from 20 to 52 years for mothers, with a mean of 6.5 years of age difference between them. Most of the participated families (i.e., 90\%) had less than 6 children and only $4 \%$ of the families had one child. The majority of the participated mothers and fathers had a college degree. About $94 \%$ of the fathers reported that they were employed compared to around $26 \%$ of the mothers.

Mothers had higher total perceived stress levels than fathers, with a mean of 17.94 and a standard deviation of $6.41 \mathrm{com}-$ pared with a mean of 15.13 and a standard deviation of 7.12 for fathers. The difference between mothers' stress levels and the fathers' is investigated in the next section. 
Table 1. Profile of the respondents

\begin{tabular}{lll}
\hline $\begin{array}{l}\text { Characterstics of the } \\
\text { parent }\end{array}$ & $\begin{array}{l}\text { Mothers n=528 } \\
\text { \% (n) }\end{array}$ & $\begin{array}{l}\text { Fathers n=528 } \\
\text { \% (n) }\end{array}$ \\
\hline $\begin{array}{l}\text { Employment status: } \\
\text { Employed }\end{array}$ & $26.3 \%(139)$ & $93.9 \%(496)$ \\
Unemployed & $73.7 \%(389)$ & $6.1 \%(32)$ \\
Educational status: & & \\
Not educated & $0.4 \%(2)$ & $0 \%(0)$ \\
Elementary school & $8 \%(42)$ & $9.7 \%(51)$ \\
High school & $39.3 \%(208)$ & $26.9 \%(142)$ \\
College & $48.7 \%(257)$ & $53.4 \%(282)$ \\
$\quad$ University/postgraduate & $3.6 \%(19)$ & $10 \%(53)$ \\
Financial status: & & \\
Financially comfortable & $33.5 \%(177)$ & $32.2 \%(170)$ \\
Financially varies & $58 \%(306)$ & $59.5 \%(314)$ \\
$\quad$ Financially tight & $8.5 \%(45)$ & $8.3 \%(44)$ \\
\hline
\end{tabular}

Table 2. Profile of the respondents

\begin{tabular}{|c|c|c|}
\hline $\begin{array}{l}\text { Characteristics of the } \\
\text { parent }\end{array}$ & $\begin{array}{l}\text { Mothers } n=528 \\
\text { mean (SD) }\end{array}$ & $\begin{array}{l}\text { Fathers n = 528 } \\
\text { mean (SD) }\end{array}$ \\
\hline Age & $35.62(5.83)$ & $42.10(6.65)$ \\
\hline Total perceived stress score & $17.94(6.41)$ & $15.13(7.12)$ \\
\hline Number of children & $3.56(1.44)$ & $3.56(1.44)$ \\
\hline $\begin{array}{l}\text { Difference in age between } \\
\text { fathers and mothers in years }\end{array}$ & $6.49(4.57)$ & \\
\hline
\end{tabular}

\subsection{Difference of parental perceived stress levels}

Table 3 shows that $p<.001$ indicating a significant difference in perceived stress levels between mothers and fathers, with mothers having significantly higher stress scores. The mean score for mothers was $17.94(\mathrm{SD}=6.41)$ compared with $15.13(\mathrm{SD}=7.12)$ for fathers, $t(527)=10.10, p<.001$. The mean difference between them was 2.81 (95\% CI: 2.26 to 3.34). The eta squared statistic $=0.16$ indicated a large effect size.

Table 3. Difference in parental PSS10

\begin{tabular}{|c|c|c|c|c|c|c|}
\hline Paired samples $t$-test & Mothers mean & Fathers mean & Mean difference & $T$ value & Df & $P$ value \\
\hline $\begin{array}{l}\text { Total maternal stress scores }- \text { total } \\
\text { paternal stress scores }(n=528)\end{array}$ & 17.94 & 15.13 & 2.81 & 10.10 & 527 & $<.001$ \\
\hline
\end{tabular}

A Pearson product-moment correlation coefficient was computed to examine the relationship between total maternal perceived stress score and total paternal perceived stress score. There was a positive correlation between the two variables ( $r$ $=0.574, \mathrm{n}=528, p<.001)($ see Table 4$)$.
Additionally, the Cronbach's alpha of this study was 0.89 for the mothers and 0.90 for the fathers and showed that this instrument is reliable to be used to measure stress for Jordanian parents.

Table 4. Correlation between maternal and paternal perceived stress levels

\begin{tabular}{llll}
\hline Variable & Total maternal perceived stress levels & Total paternal perceived stress levels & $\boldsymbol{P}$ value \\
\hline Total maternal perceived stress levels & 1 & 0.574 & $<.001$ \\
Total paternal perceived stress levels & 0.574 & 1 & $<.001$ \\
\hline
\end{tabular}

\section{Discussion}

In the current study, we aimed to recruit 500 couples and we got 528. Our participants demographical data showed that approximately $90 \%$ of couples participating had high school education and above. According to the department of statistics in Jordan, more than $90 \%$ of the Jordanian population who are above 15 years old are able to read and write. ${ }^{[31]}$ The high level of education among the sample may be because the mean age for fathers was around 42 years and for mothers was around 36 years and previous literature showed that educational status is the lowest among people who are 50 years old and above in Jordan. ${ }^{[20,32]}$

In addition, in this study fathers were enrolled in work life more than mothers. Approximately $94 \%$ of the fathers and $26 \%$ of the mothers in this sample were employed. This is 92 consistent with the Jordanian statistics indicated that $73 \%$ of married women are housewives. ${ }^{[20]}$ In Jordan, caring for children and managing house duties are the main roles of mothers in Islamic and cultural point of view. Moreover, the average of number of children in the family in this sample was 3.5; this is consistent with the Jordanian statistics showed that the average number of household members in Jordan (including mother, father and the children) is 5.4. ${ }^{[20]}$ Furthermore, participants were couples parenting children in various major cities in Jordan (i.e., more than $70 \%$ of Jordanian population are living in these cities). ${ }^{[20]}$ Thus, we can say that our sample is representative of mothers and fathers parenting children in Jordanian population.

This Jordanian study showed that mothers and fathers parenting children in Jordan reported higher PSS10 than the US 
adult normal population indentified by Cohen (i.e., Jordanian mothers and fathers reported 17.94 and 15.13 respectively while adult females and males in the US reported 13.7 and 12.1 respectively). ${ }^{[21]}$ Parental stress level in our study was lower than the Jordanian students identified by HamdanMansour and Dawani (i.e., Jordanian female and male university students reported 22.7 and 21 , respectively). ${ }^{[22]}$ The difference in the stress levels between various studies may be because of the differences of the age groups, life responsibilities and cultural variations.

Mothers and fathers in the Jordanian population have different roles and responsibilities. For example, mothers are more responsible for the children care, household responsibilities, cleaning and preparing food while many of them work to support the family financially. ${ }^{[33]}$ Motherhood needs psychological readiness, physical effort and enough time leaving mothers unable to find a space for themselves, their own activities, social connections, friends and time to spend with their partners as couples. Moreover, in the Arab world many women may have children because of the social pressure they face. ${ }^{[33]}$ Those might not be ready for motherhood. All of these may have an impact on their stress levels.

Women in general were found to be more emotional and used to report higher stress levels than men even when face the same stressors. ${ }^{[17]}$ Mothers in this study reported significantly higher stress scores than fathers. This is aligned with many studies found that females reported higher stress levels than males in various life situations. ${ }^{[22,34,35]}$ Especially, when stress relates to social life e.g. relationships and family relations, children, home setting, family health, well-being and work environment. ${ }^{[36]}$

In the current research study, the higher mothers' stress levels were associated with higher fathers' stress scores and vice versa. Parents participated in this study were couples sharing almost similar life circumstances, financials and most importantly they parenting the same children. Therefore, parents' stress levels were likely to be high or low together. Although this study reported that mothers' stress scores were higher than their partners, high stress levels for both parents were positively related to each other.

Many of the reviewed stress studies focused on the individual stress levels and ignored the potential effect of a stress level of a family member on the surrounding people. The results of this study illustrated that mothers and fathers stress are correlated. This is consistent with Kim et al. who investigated stress levels in couples where one of them had cancer and found that stress might be seen as a dynamic of a unit and not only as an individual. ${ }^{[37]}$ Additionally, researchers believed that not only your own stress level can affect your

Published by Sciedu Press health but also your spouse stress level can affect you as well. ${ }^{[37]}$ Other researchers studied the crossover of stress between partners. For example, Bakker et al. found that stress might be transmitted from husband to wives and vice versa, affecting their psychological status. ${ }^{[38]}$

\subsection{Strength and weakness of the current study}

Findings gained from this study can be considered the first to report the differences in perceived stress levels of couple's parents in Jordanian population. The large range and size of the research was a notable factor. The level of the study was significant, as 1056 respondents parents completed the survey questions and all of them were couples. In addition, the schools chosen in this study are reflecting different geographically places and covering a widespread area in the country. In the current study, due to the fact that the couples of mothers and fathers were all sharing almost the same demographical, life situations and cultural issues, PSS10 results were expected to be able to reflect any gender differences in perceived stress scores among them. The use of a specific questionnaire may have restricted the generalisability of these findings, because of the limited factors that the tool actually measures. Furthermore, parents were instructed to fill in the questionnaires independently, as the researcher could not be with the respondents while filling in the questionnaires to ensure that. However, it was clearly stated in the information sheets and the questionnaires the importance of filling the questionnaire independently.

\subsection{Implications}

Results gained from this study may be used to make a comparison of stress levels between mothers and fathers of healthy children and those parenting children with any specific condition in Jordan. Moreover, the availability of an Arabic version of PSS10 makes it a useful instrument for researchers conducting projects that measure perceived stress in various Arab countries.

Measuring stress reliably taking in consideration the effect of gender would be helpful to clarify the link between stress and health for both genders. Consequently, we recommend that stress relieving interventions should be based on gender and that male may need different stress management strategies than females.

\section{Conclusions}

Stress is considered a risk factor for several chronic diseases such as hypertension, coronary artery disease, etc. Stress differs across different genders, cultures, countries and communities. In this study, the Arabic translated version of the PSS10 showed reasonably adequate psychometric properties. 
Jordanian mothers and fathers reported high stress levels; mothers reported more stress than fathers. This may indicate that Jordanian mothers and fathers face different demands and get different resources to deal with stress.

\section{ACKNOWLEDGements}

The authors are grateful to the Applied Science Private Uni- versity, Amman, Jordan, for the partial financial support granted to this research project and for the financial support granted to cover the publication fee of this research article.

\section{CONFLicts OF InTEREST Disclosure}

The authors declared that they have no competing interest.

\section{REFERENCES}

[1] Cohen S, Janicki-Deverts D, Miller GE. PSychological stress and disease. JAMA. 2007; 298(14): 1685-1687. PMid:17925521 http: //dx.doi.org/10.1001/jama.298.14.1685

[2] Masa'Deh R, et al. Predictors of Stress of Parents of a Child with Cancer: A Jordanian Perspective. Global Journal of Health Science. 2013; 5(6): 81. PMid:24171877 http://dx.doi.org/10.5539/g jhs.v5n6p81

[3] Masa'Deh R, Collier J, Hall C. Parental stress when caring for a child with cancer in Jordan: a cross-sectional survey. Health and Quality of Life Outcomes. 2012; 10(1): 88. PMid:22838940 http://dx.doi.org/10.1186/1477-7525-10-88

[4] Pelchat D, Lefebvre H, Levert MJ. Gender differences and simililarities in the experience of parenting a child with a health problem: current state of knowledge. Journal of Child Health Care. 2007; 11(2): 112-131. PMid:17494986 http://dx.doi .org/10.1177/13674 93507076064

[5] Lazarus RS. Stress and Emotion: A New Synthesis: New York: Springer Publishing Company; 2006. 342.

[6] Song Z, et al. Unraveling the Daily Stress Crossover between Unemployed Individuals and Their Employed Spouses. Journal of Applied Psychology. 2011; 96(1): 151-168. PMid:20919793 http://dx.doi.org/10.1037/a0021035

[7] Melinda Smith MA, Segal J. Coping with Grief and Loss. 2014.

[8] Aldwin CM, Werner EE. Stress, Coping, and Development, Second Edition: An Integrative Perspective. Guilford Publications; 2009.

[9] Cohen S, Janicki-Deverts D. Who's Stressed? Distributions of Psychological Stress in the United States in Probability Samples from 1983, 2006, and 20091. Journal of Applied Social Psychology. 2012; 42(6): 1320-1334. http://dx.doi.org/10.1111/j.1559-181 6.2012.00900.x

[10] Eaton RJ, Bradley G. The Role of Gender and Negative Affectivity in Stressor Appraisal and Coping Selection. International Journal of Stress Management. 2008; 15(1): 94-115. http://dx.doi.org/1 $0.1037 / 1072-5245.15 .1 .94$

[11] Tamres LK, Janicki D, Helgeson VS. Sex Differences in Coping Behavior: A Meta-Analytic Review and an Examination of Relative Coping. Personality and Social Psychology Review. 2002; 6(1): 2-30. http://dx.doi.org/10.1207/S15327957PSPR0601_1

[12] Verma R, Balhara Y, Gupta C. Gender differences in stress response: Role of developmental and biological determinants. 2011; 20: 4-10.

[13] Muhonen T, Torkelson E. The Demand-Control-Support Model and Health Among Women and Men in Similar Occupations. Journal of Behavioral Medicine. 2003; 26(6): 601-613. PMid:14677214 http://dx.doi.org/10.1023/A:1026257903871

[14] Tomova L, et al. Is stress affecting our ability to tune into others? Evidence for gender differences in the effects of stress on self-other distinction. Psychoneuroendocrinology. 2014; 43: 95-
104. PMid:24703175 http://dx.doi.org/10.1016/j.psyneue n. 2014.02.006

[15] Sipal RF, et al. Course of behaviour problems of children with cerebral palsy: the role of parental stress and support. Child: Care, Health and Development. 2010; 36(1): 74-84. PMid:19702640 http://dx.doi.org/10.1111/j.1365-2214.2009.01004.x

[16] Moh TA, Magiati I. Factors associated with parental stress and satisfaction during the process of diagnosis of children with Autism Spectrum Disorders. Research in Autism Spectrum Disorders. 2012; 6(1): 293-303. http://dx.doi.org/10.1016/j.rasd.2011.05.011

[17] Shatla R, et al. Correlates of parental stress and psychopathology in pediatric epilepsy. Annals of Indian Academy of Neurology. 2011; 14(4): 252-256. PMid:22346012 http://dx.doi.org/10.4103 10972-2327.91938

[18] Neece CL. Mindfulness-Based Stress Reduction for Parents of Young Children with Developmental Delays: Implications for Parental Mental Health and Child Behavior Problems. Journal of Applied Research in Intellectual Disabilities. 2014; 27(2): 174-186. PMid:23813562 http://dx.doi.org/10.1111/jar.12064

[19] Bayat M, Erdem E, Gul Kuzucu E. Depression, Anxiety, Hopelessness, and Social Support Levels of the Parents of Children With Cancer. Journal of Pediatric Oncology Nursing. 2008; 25(5): 247253. PMid:18648089 http://dx. doi .org/10.1177/104345420 8321139

[20] Jordanian Department of Statistics. Jordanian statistics, at End-year 2010. Available from: http://www.dos.gov.jo/dos_home_e/ main/jorfig/2008/jor_f_e.htm

[21] Cohen S, Williamson G. Perceived stress in a probability sample of the United States, in the social psychology of health: Claremont Symposium on applied social psychology, S. Spacapan and S. Oskamp, Editors; 1998. 31-67.

[22] Hamdan-Mansour A, Dawani H. Social Support and Stress among University Students in Jordan. International Journal of Mental Health and Addiction. 2008; 6(3): 442-450. http://dx.doi .org/10.10 07/s11469-007-9112-6

[23] Dr. Cohen's Scales. http://www.psy.cmu.edu/ scohen/scal es.html. 2011

[24] Hattar-Pollara M, Dawani H. Cognitive Appraisal of Stress and Health Status of Wage Working and Nonwage Working Women in Jordan. Journal of Transcultural Nursing. 2006; 17(4): 349356. PMid:16946117 http://dx.doi.org/10.1177/104365960 6291543

[25] Chaaya M, et al. Validation of the Arabic version of the Cohen perceived stress scale (PSS-10) among pregnant and postpartum women. BMC Psychiatry. 2010; 10(1): 111. PMid:21159169 http: //dx.doi.org/10.1186/1471-244X-10-111

[26] Cohen S, Kamarck T, Mermelstein R. A global Measure of Perceived Stress. Journal of Health and Social Behavior. 1983; 24(1): 386-396. http://dx.doi.org/10.2307/2136404 
[27] Almadi T, et al. An Arabic version of the Perceived Stress Scale: Translation and validation study. International Journal of Nursing Studies. 2012; 49(1): 84-89. PMid:21851941 http://dx.doi.org /10.1016/j.ijnurstu.2011.07.012

[28] Cohen S, Williamson G. Perceived stress in a probability sample of the United States, in the social psychology of health: Claremont Symposium on applied social psychology, S. Spacapan and S. Oskamp, Editors. 1988. 31-67.

[29] George D, Mallery P. IBM SPSS Statistics 21 Step by Step: A Simple Guide and Reference. Pearson Education. 2013

[30] Pallant J. SPSS survival manual: a step by step guide to data analysis using SPSS for Windows (version 15). Crows Nest, N.S.W.: Allen \& Unwin. 2007.

[31] Jordanian Department of Statistics. Jordanian statistics, at End-year. 2007. Available from: http://www.dos.gov.jo/jorfig/2007 /jor_f_e.htm

[32] Al-Khaldi MD. Educational Attainment of Jordan's Population and Labor Force. Journal of Social Sciences. 2006; 2(1): 1-6. http: //dx.doi.org/10.3844/jssp.2006.1.6
[33] Jordanian Higher Council for Youth, National Youth Strategy for Jordan. 2009; 1-23.

[34] Hall N, et al. Primary and Secondary Control in Academic Development: Gender-specific Implications for Stress and Health in College Students. Anxiety, Stress and Coping. 2006; 19: 189-210. http://dx.doi.org/10.1080/10615800600581168

[35] Tytherleigh MY, et al. Gender, Health and Stress in English University Staff Exposure or Vulnerability? Applied Psychology An International Review. 2007; 56: 267-287. http://dx.doi.org/1 $0.1111 / j .1464-0597.2006 .00254 . x$

[36] Vrijmoet-Wiersma C, et al. Assessment of parental psychological stress in pediatric cancer: A review. Journal of Pediatric Psychology. 2008; 33(7): 694-706. PMid:18287109 http://dx.doi.org/10 . 1093/jpepsy/jsn007

[37] Kim Y, et al. Individual and dyadic relations between spiritual wellbeing and quality of life among cancer survivors and their spousal caregivers. Psycho-Oncology. 2010; 20(7): 8.

[38] Bakker AB, Demerouti E, Schaufeli WB. The crossover of burnout and work engagement among working couples. Human Relations. 2005; 58(5): 661-689. http://dx.doi.org/10.1177/0018726 705055967 